\title{
Allergen Extraction: Factors Influencing Immunogenicity and Sensitivity of Immunoassays
}

\author{
João Ricardo Almeida Soares ${ }^{1}$, Airton Pereira e SIlva ${ }^{1}$, Isabelle Guimarães ${ }^{1}$, Ana Luisa \\ Oliveira $^{1}$, Claudia Regina Faccini ${ }^{1}$, Erika Mattos ${ }^{1}$, Sónia Rodrigues ${ }^{1}$, Bárbara Marmello ${ }^{1}$, \\ and Gerlinde Teixeira ${ }^{1}$ \\ ${ }^{1}$ Universidade Federal Fluminense
}

March 9, 2021

\begin{abstract}
Because of the high social impact of Food allergy, it is of great importance to correctly diagnose this disease using reliable tests. Knowledge of the allergenicity properties of proteins, how they react in the body and in diagnostic tests is necessary to adequately assess the potential immunogenicity of both natural foods and those produced through biotechnological processes. Thus, our aim was to analyze the factors that influence the protein extraction of foods in terms of, immunogenicity and immunoassays sensitivity. Peanut proteins were extracted using four distinct extraction buffers (physiological saline, tris buffer, borate buffer with and without $\beta$-mercaptoethanol), the protein concentration was determined by the Lowry method and polyacrylamide electrophoresis (SDS-PAGE) was used to compare the protein profile of each extract. The immunogenicity of each extract was verified by sensitizing two mouse strains (Balb/c and C57/BL6) with solution containing 100ug of the extracted proteins and determined by ELISA. Results show that extraction with the distinct buffers resulted in protein solutions with different yields and profiles. The immunogenicity of the different extracts also demonstrated distinct patterns that varied depending on the extraction methods, mouse strain and in-vitro test. Immunoreactivity varied in accordance to the protein extract used to coat the microtitration plates. In conclusion, the protein profile in the extracts is critically influenced by the salt composition and $\mathrm{pH}$ of the extraction buffers, this in turn influences both in vivo immunogenicity and in vitro immunoreactivity.
\end{abstract}

\section{Introduction}

"The term immunogenicity refers to the ability of a substance to induce cellular and humoral immune response, while antigenicity is the ability to be specifically recognized by the antibodies generated because of the immune response to the given substance. While all immunogenic substances are antigenic, not all antigenic substances are immunogenic." [1]

Allergies have a high social impact, $4 \%$ to $8 \%$ of children are diagnosed as allergic and a significant portion of these present symptoms that prevent school attendance, which in turn, takes at least one of their caregivers away from work [2-4]. In addition to absence at work, altering meal-preparation routine and other family social activities negatively impacts stress levels [5]. Thus, adequate diagnosis is fundamental.

The best-known measure to prevent food allergy symptomatology is the adoption of exclusion diets and to ensure clearer food labeling many countries have food allergen labeling laws. For example, the Food Allergen Labeling and Consumer Protection Act (FALCPA/USA-2004) requires that foods are labeled to identify the eight major food allergens: milk, egg, fish, crustacean-shellfish, tree nuts, wheat, peanuts and soybeans which account for over $90 \%$ of all documented food allergies in the U.S. [6] A Along with these 8 the Australian law requires the labeling of two other foods - sesame and lupin [3]. In the European Union 14 foods are on the required labeling list: the ten previously cited plus celery, mustard, Sulphur dioxide, and mollusks. [4] 
Regardless of whether ingested food is derived from animals or plants, the food matrix is composed of varying amounts of proteins, carbohydrates, and fats. To perform reliable analysis of each macronutrient, several techniques have been developed to obtain adequate quantities of purified material with a minimum of structural and functional loss. For this, the main steps are: extraction, quantification, biological function determination, sequence and structure identification [7]. Among the resources used in food protein analysis, the first step is the physical fragmentation of solid foods. This increases the contact surface of the food with the buffers during incubation, permitting a more efficient extraction [8]. Acidic, neutral, or alkaline molecules are preferentially extracted when specific buffers with different salts and ionic strengths are employed. The efficiency of these buffers may vary according to the food matrix, thus altering the protein yield resulting from the extraction process [9]. Once a protein extract is obtained, quantification is a fundamental procedure influencing the registered protein content of foods. The three most frequently used indirect methods are based on Lowry, Bradford and Kjeldahl techniques [10] [11]. The main objective of this study was to document the protein immunogenicity and sensitivity in immunoassays, as the result of different extraction buffers, of a seed considered to be extremely immunogenic.

\section{Materials and Methods}

\section{Peanut protein Extraction}

Peanut (Combrasil - 13L02MCN0049) protein extraction was performed as described by Landry [8], and adapted by Teixeira [12]. In short, seeds were milled in an electric coffee grinder (Philco PERFECT COFFEE 127V model 53901040) and passed through a fine stainless-steel sieve. Samples of peanut flour were placed in 4 Falcon tubes. To each of the tubes containing the seed flours we added one of the buffers to be tested at a final ratio of $1: 10 \mathrm{w} / \mathrm{v}$. Namely borate buffer (BB), borate buffer with addition of $2 \% \beta$-mercaptoethanol (Sigma-Aldrich, São Paulo, Brazil, M3701) (BB-2ßME), saline buffer (SB) or Tris/HCl buffer (TB/HCl). All 4 tubes were then placed on a rocker at room temperature for an hour. The material of each tube was paper-filtered, and the eluted solution (crude extract) was centrifuged three times at $5^{\circ} \mathrm{C}$ and $28,000 \mathrm{x}$ $g$ for 15 minutes (IEC - International Centrifuge, model PR-2, Needham, MA, USA). At the end of each centrifugation, the top layer (containing fat) and the seed precipitate were discarded. The intermediate supernatants were collected, recentrifuged or aliquoted and stored at -20degC until use. Thus, we obtained four crude peanut extracts: crude peanut extract - Borate Buffer (CPE-BB), crude peanut extract - Borate Buffer $+2 \% \beta$-mercaptoethanol (CPE-BB2 $\beta M E)$, crude peanut extract - Saline Buffer (CPE-SB), Crude Peanut Extract - Tris/HCl Buffer $(\mathrm{CPE}-\mathrm{TB} / \mathrm{HCl})$.

\section{Protein quantification, SDS-PAGE and immunoblotting}

Protein quantification of the crude extracts was determined by the Lowry technique [11]. Protein profile was analyzed using $15 \%$ sodium dodecyl sulfate polyacrylamide gel electrophoresis (SDS-PAGE) as described by Laemmli [13] and stained with Coomassie Brilliant Blue (Bio-Rad, Rockville Centre, NY 11571) [14]. Immunoblotting, to study the immunoreactivity of the proteins was performed as described by Towbin et al [15].

\section{In Vivo Experiments}

All procedures and number of animals for this work were approved by the university's animal ethical committee under the permit number 781. This study follows the ARRIVE guidelines [16].

Adult ( 8 weeks old) female C57BL/6 $(\mathrm{n}=20)$ and Balb/c $(\mathrm{n}=20)$ mice were obtained from the local animal breeding facility (Núcleo de Criação de Animais de Laboratório - NAL - UFF) and kept in the experimental animal-room of the Immunobiology Department during the whole protocol. Animals were kept in polystyrene cages with steel covers in a conventional environment with acidified water, which is widely used in animal colonies to prevent the spread of bacterial diseases [17, 18], and commercial mouse chow ad libitum (temperature of $22^{\circ} \mathrm{C}, \sim 60 \%$ humidity and 12-hours light/ 12-hours dark cycle) and each strain was divided in four groups of 5 mice ( $\mathrm{n}=5$ per group). 
Mice were submitted to a food allergy induction protocol described by Teixeira (2009). In short 100ug of protein extract was introduced twice subcutaneously with a three-week interval. To the primary inoculation, $1 \mathrm{mg}$ of alum $\left(\mathrm{Al}(\mathrm{OH})_{3}\right)$ was added.

\section{Immunogenicity/immunoreactivity}

Anti-peanut antibodies were tittered using ELISA. In short, each of the 96 wells of the microtitration plates (Global Plast, China, 655111T) was adsorbed with $100 \mu$ l of saline buffer containing $2 \mu \mathrm{g}$ of the specific protein extract. A 3-fold serial dilution of the sera was performed, and HRP goat anti-mouse $\gamma$-chain was used (SIGMA, Saint Louis, MO, United States A9044). The result was registered using a microtitration plate reader (Anthos 2010?, Biochrom, Cambourne, Cambridge, UK). Reactivity analysis was performed by comparing the area under the dilution curve. The serum of each mouse was tested 4 -fold, i.e. on four microtitration plates adsorbed each, with one of the 4 protein extracts.

\section{Statistical Analysis}

We considered a minimum of five animals per group. The parameters used to display the results were mean and standard deviation. First, Shapiro-Wilk test was used for normal distribution evaluation. Then, outliers were removed using Grubbs test. Finally, the minimum significance level with 95\% confidence interval (p) was calculated using Student's T-test when comparing two groups or one-way analysis of variance (ANOVA) with Tukey-Kramer post-test when comparing multiple groups (multiplicity adjusted p-value). All statistical tests were performed on GraphPad Prism ${ }^{\circledR} 6.01$ software by GraphPad Software, Inc. (La Jolla, CA, USA).

\section{RESULTS}

\section{Protein quantification}

We observed that the four extraction buffers rendered significantly different protein concentrations for peanuts (Figure 1). The highest CPE yield was obtained with BB2ßME $(22,82 \pm 1,19 \mathrm{mg} / \mathrm{mL})$ followed by SB $(20,94 \pm 2,33 \mathrm{mg} / \mathrm{mL}), \mathrm{BB}(18,72 \pm 2,92 \mathrm{mg} / \mathrm{mL})$ and TB/HCL $(12,99 \pm 2,32 \mathrm{mg} / \mathrm{mL})$. These results show the different extraction potential of each buffer. Considering the use of 10 grams of the seed and $100 \mathrm{~mL}$ of each extraction buffer the final CPE yield was as follows: BB2ßME (62.9\%); SB (59.3\%), BB (51,6\%) and TB/HCL $(38.2 \%)$. The final volume obtained of each extract did not significantly influence the total protein extraction BB2ßME $(75 \mathrm{~mL})$; $\mathrm{SB}(77 \mathrm{~mL}), \mathrm{BB}(75 \mathrm{~mL})$ and TB/HCL $(80 \mathrm{~mL})$.

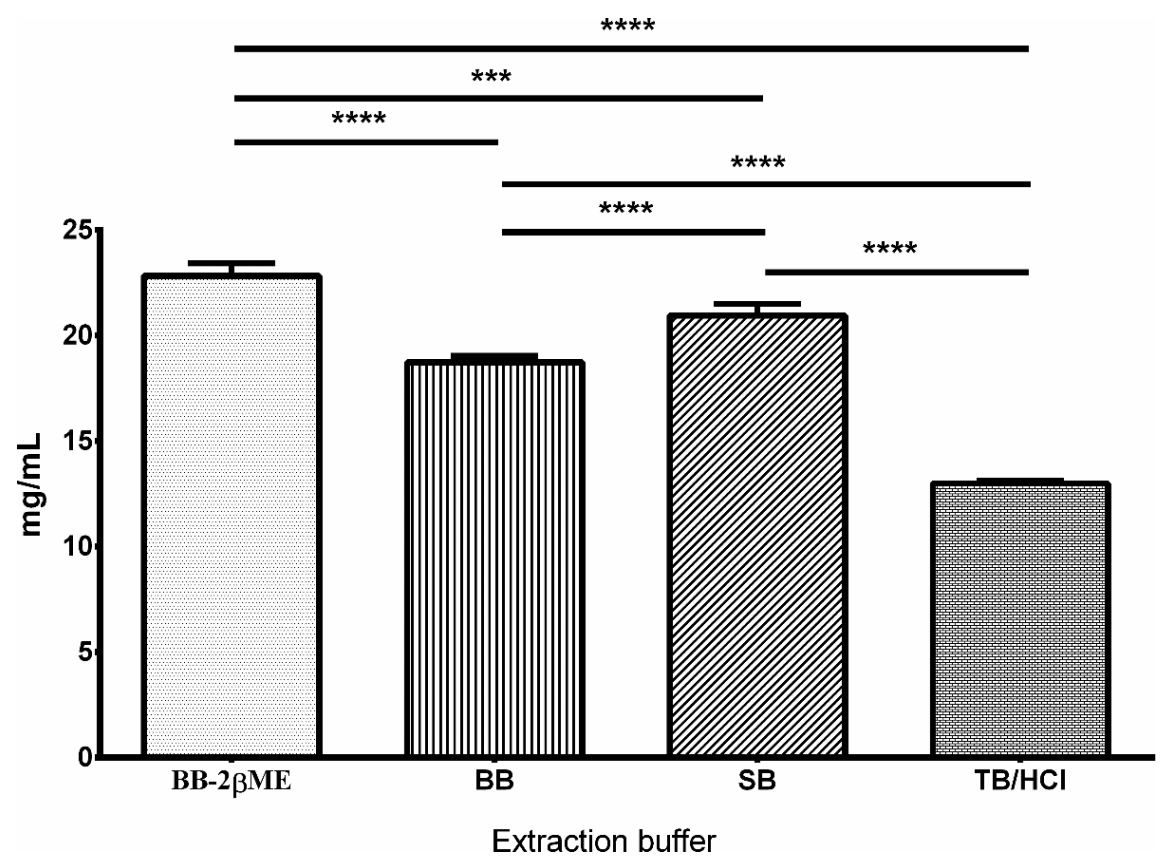


Fig 1. Peanut protein extract yield : Crude peanut protein extracts (CPE) obtained with BB-2ßME, $\mathrm{BB}, \mathrm{SB}$ and $\mathrm{TB} / \mathrm{HCl}(\mathrm{B})$ final yield obtained with $\mathrm{BB}-2 \beta \mathrm{ME}, \mathrm{BB}, \mathrm{SB}$ and $\mathrm{TB} / \mathrm{HCl} ; \mathrm{p}<0.05={ }^{*} ; \mathrm{p}<0.01$ $=* * ; \mathrm{p}<0.001=* * * ; \mathrm{p}<0.0001=* * * *$

\section{Electrophoresis - Protein profile determination and immunoblotting}

In comparison to $\mathrm{BB}$ the use of BB-2ßME led to a shift in the electrophoretic protein pattern of CPE in which some of the higher molecular weight bands reduce in intensity (white double arrow - Fig. 2) and others disappear. The pattern of protein bands obtained with SB is similar to that obtained with BB. However, SB solubilized better the higher and lower molecular weight bands. The immunoblot reactivity showed that the greatest reactivity with sera of animals immunized by CPE-BB-2 $\beta \mathrm{ME}$ and $\mathrm{CPE}-\mathrm{TB} / \mathrm{HCl}$ to their corresponding extract (Fig. 3).

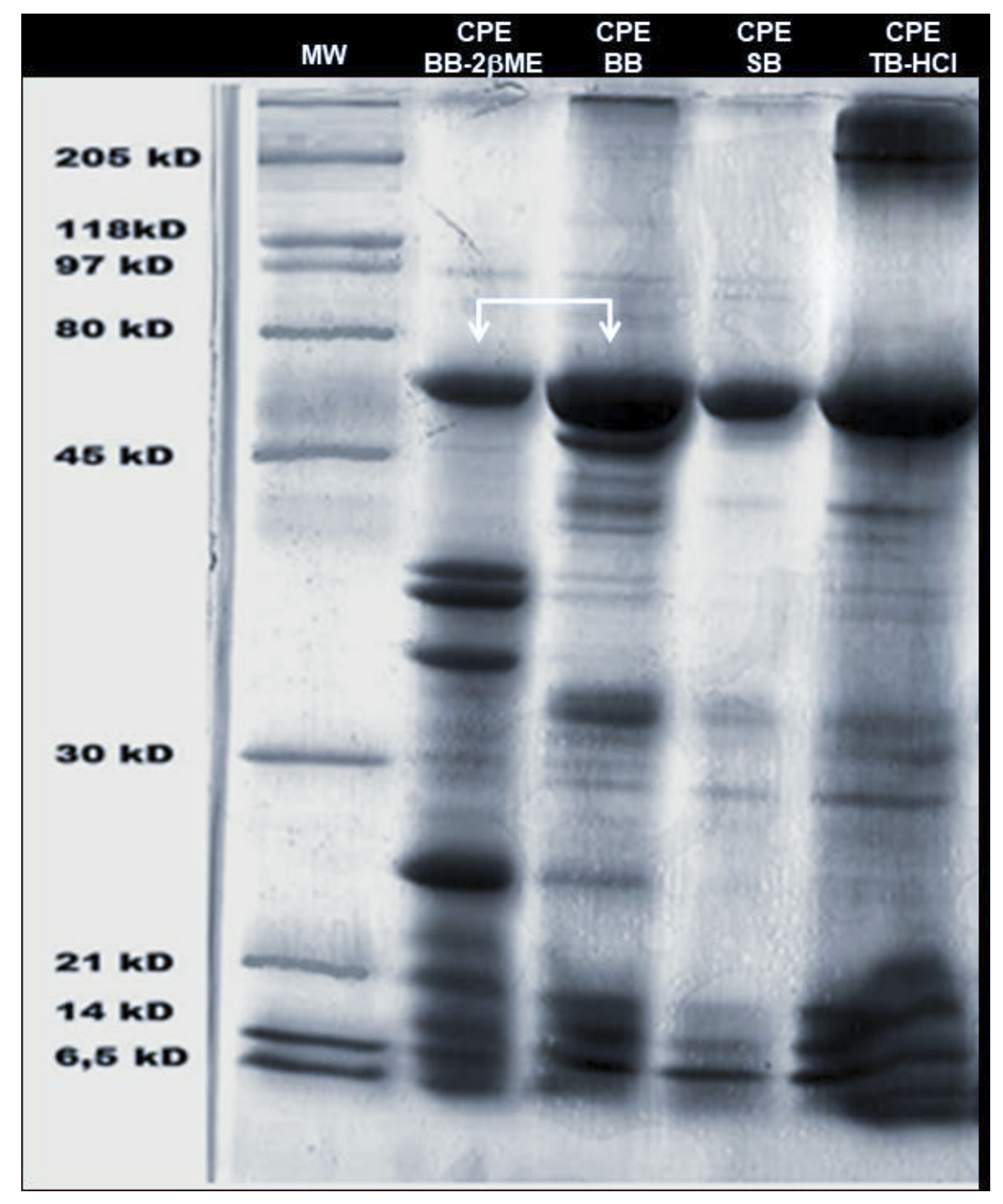

Fig 2. SDS-PAGE - 15\% polyacrylamide gels showing the band profile of peanut extracts. The gels were stained with Coomassie Brilliant Blue. The first column shows the molecular weight bands (MW).

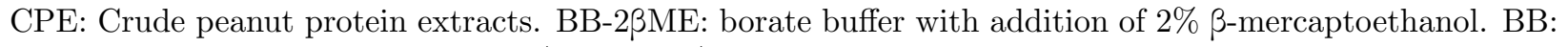
borate buffer. SB: Saline buffer. TB/HCl: Tris/HCl buffer. 


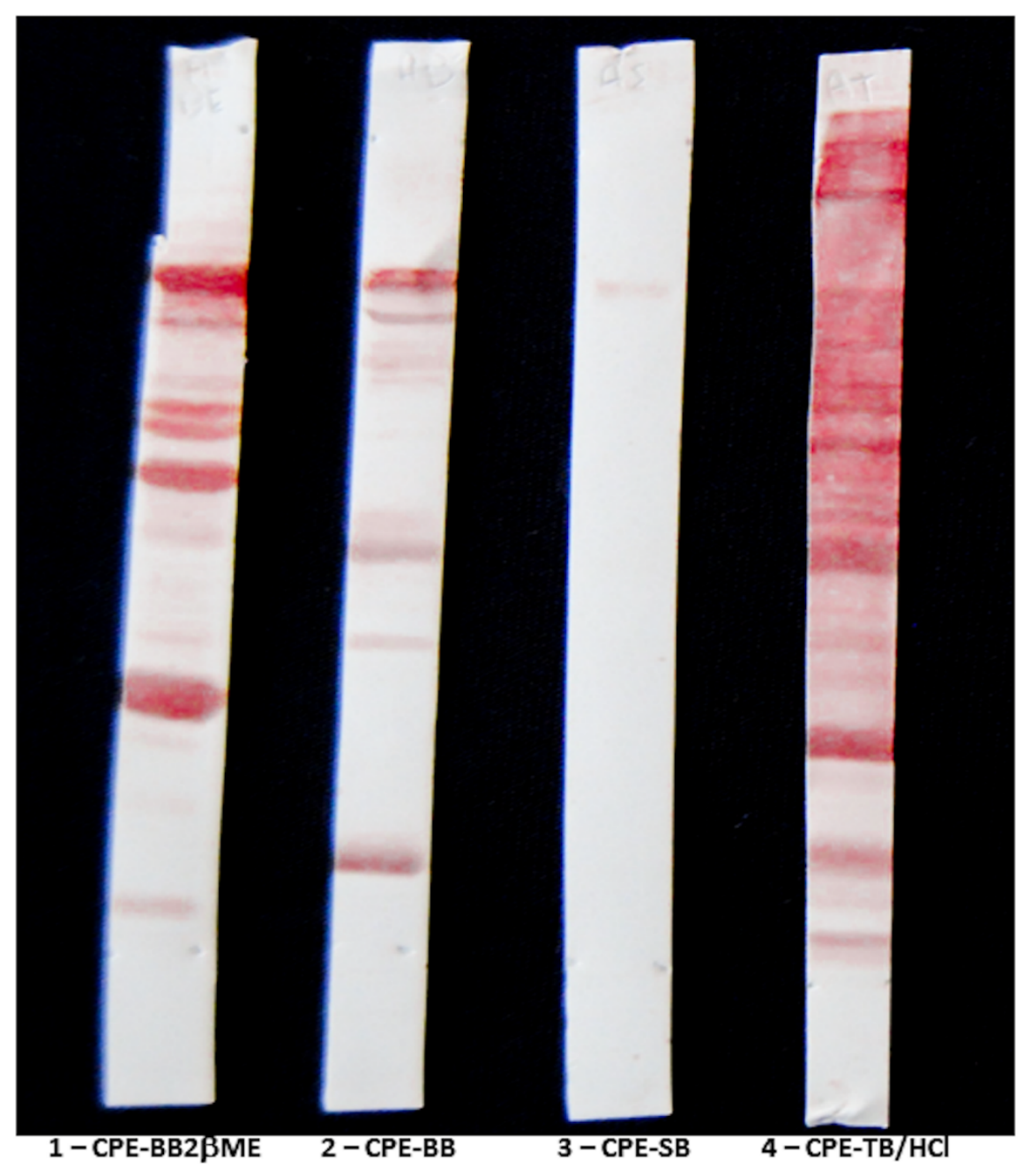

Fig 3. Immunoblotting - Reactivity of a pool of 5 sera to the corresponding sensitization extracts. CPE: Crude peanut protein extracts. BB-2 $\beta$ ME: borate buffer with addition of $2 \% \beta$-mercaptoethanol. BB: borate buffer. SB: Saline buffer. TB/HCl: Tris/HCl buffer.

\section{Immunogenicity/immunoreactivity}

All four CPEs were immunogenic for both mouse strains tested. All sera showed positive results when reacting to the homologous protein extract coated on the ELISA plate. There were no significant intergroup differences in serum reactivity of CPE sensitized C57BL/6 mice (Fig 4A). However, significant differences in reactivity of sensitized Balb/c mice were observed (Fig 4B). Animals sensitized with CPE-BB2ßME and those sensitized with CPE-BB presented significantly higher mean polyisotypic IgG antibody titers $(\mathrm{p}<0.01$ and $\mathrm{p}<0.001$, respectively) than those sensitized with $\mathrm{CPE}-\mathrm{TB} / \mathrm{HCl}$ and animals sensitized with $\mathrm{CPE}-\mathrm{BB}$ presented significantly higher mean antibody titers $(\mathrm{p}<0.05)$ than those sensitized with CPE-SB (Fig 4B). 
C57BL/6

A

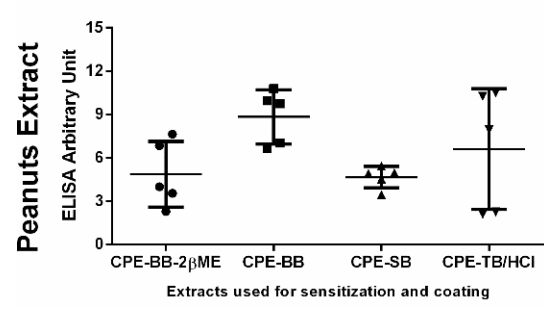

$B A L B / C$

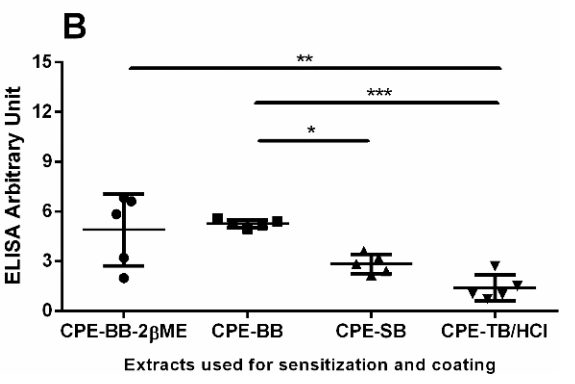

An intriguing observation is the intragroup variation for C57BL/6 mice sensitized with any of the four CPE compared to a lower variation of Balb/c mice to the same protein extracts except for CPE- BB2 $\beta M E$ (Fig $4)$.

Fig 4. Titer of the sera of C57BL/6 mice (A) and Balb/c mice (B) sensitized with Crude peanut extracts tested on ELISA plates adsorbed with the antigens corresponding to the immunization. $\mathrm{N}=5 . \mathrm{p}<0.05=^{*} ; \mathrm{p}<0.01=* * ; \mathrm{p}<0.001=* * * ; \mathrm{p}<0.0001=* * * *$

Next we examined whether different protein extracts of a given seed used to coat polystyrene microtitration plates influenced the antibody titers. Plates coated with CPE-BB2ßME (Fig 5A) or CPE-TB/HCl (Fig $5 \mathrm{D})$ did not distinguish sera reactivity derived from C57BL/6 mice sensitized with any of the four peanut extracts. However, the same sera from CPE-BB2ßME sensitized animals showed significant differences when compared to sera of those sensitized with CPE-BB on plates adsorbed with either CPE-BB (Fig 5B) or CPE-SB (Fig $5 \mathrm{C})(\mathrm{p}<0.05$ and $\mathrm{p}<0.01$, respectively). Thus, the reactivity pattern differs according to the protein extract used to coat the microtitration plates.

\section{C57BL/6}
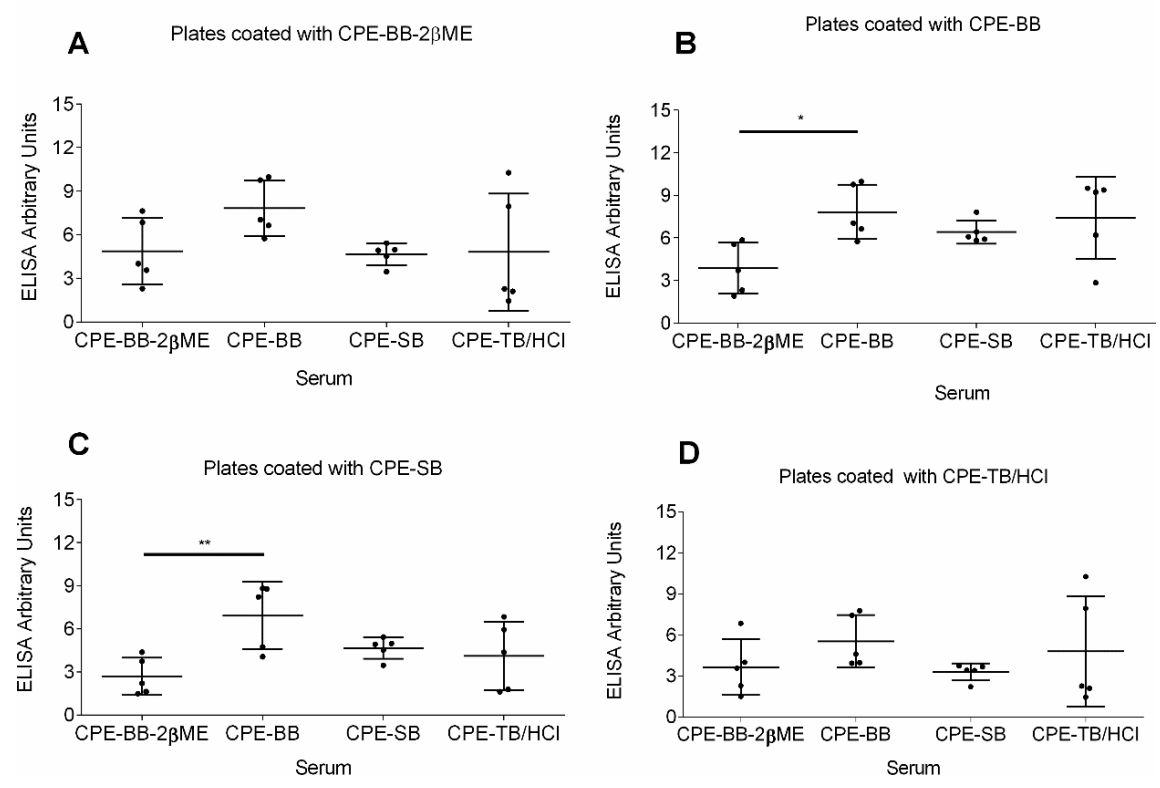

Fig 5. Titers of C57Bl/6 mice sensitized with CPE tested on ELISA plates adsorbed with A) CPE-BB2ßME; B) CPE-BB; C) CPE-SB and D) CPE-TB / HCl. N $=5 . \mathrm{p}<0.05={ }^{*}$; p <0.01 = **; $<0.001=* * * ; \mathrm{p}<0.0001=* * * *$ 
Sera from Balb/c mice sensitized with one of the four CPE and tested on CPE-BB2ßME adsorbed plates (Fig $6 \mathrm{~A}$ ) showed significant differences in reactivity. Although sera from CPE-BB2ßME and CPE-BB sensitized mice presented similar mean antibody titers the intragroup variation was significantly different. The first showed a high, while the second a low, titer dispersion. Serum from CPE-BB2ßME and CPE-BB sensitized animals developed significantly higher antibody titers than CPE-SB and CPE-TB/HCl ( $<<0.001)$. On CPE$\mathrm{BB}$ adsorbed plates (Fig 6B), serum from CPE-BB developed significantly higher antibody titers than CPE-BB2BME $(p<0.05)$. The sera from these same four CPE sensitized animals presented no intergroup differences in reactivity when tested on CPE-SB (Fig 6C) or CPE-TB/HCl (Fig 6D) coated plates.

\section{BALB/c}
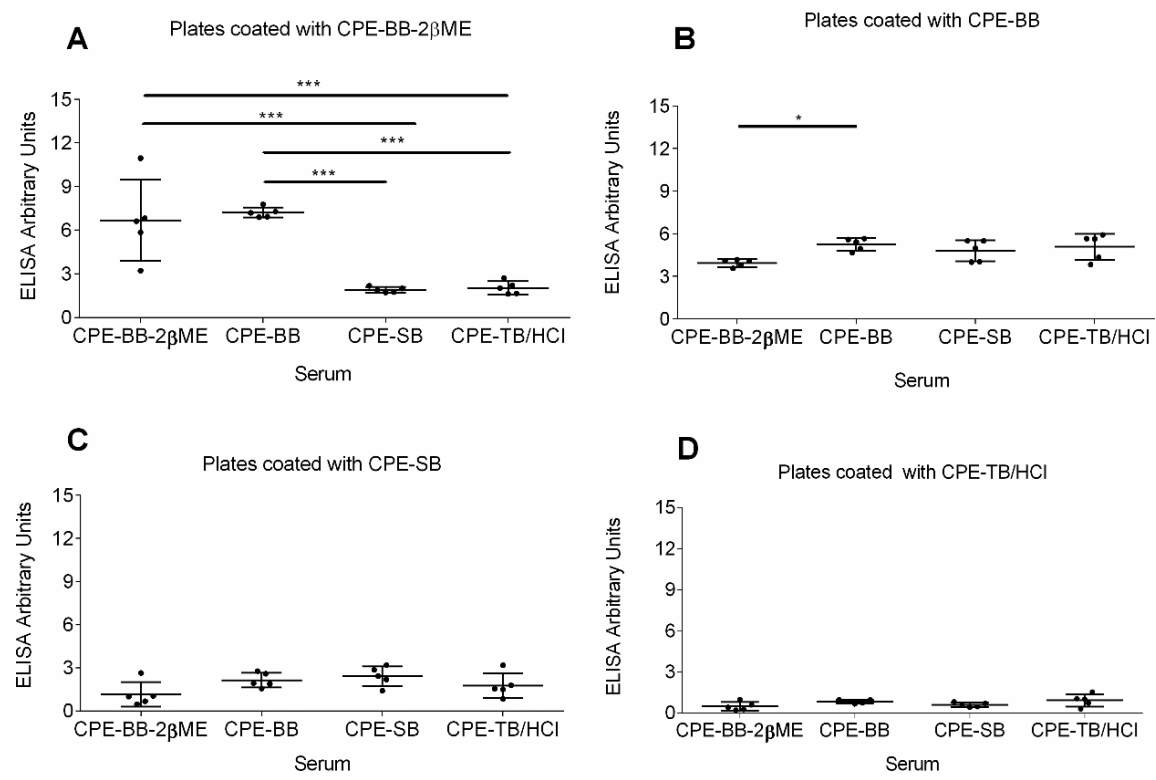

Fig 6. Serum reactivity of $\mathrm{Balb} / \mathrm{c}$ mice sensitized with peanut extracts tested on ELISA plates adsorbed with A) CPE-BB2 $3 \mathrm{ME}$; B) CPE-BB; C) CPE-SB and D) CPE-TB / HCl. N = 5. p <0.05 =*; p $<0.01={ }^{* *} ; \mathrm{p}<0.001=* * * ; \mathrm{p}<0.0001=* * * *$

Next, we performed an inter-lineage comparison using the sera derived from Balb/c and C57BL/6 mice that were sensitized and tested on ELISA plates coated with the homologous extract. No inter-strain differences were observed in CPE-BB2ßME, or CPE- TB/HCl reactivity. However, CPE-BB and CPE-SB $(\mathrm{p}<0.05)$ induced higher antibody titers in C57BL/6 mice than in Balb/c (Fig 7). 

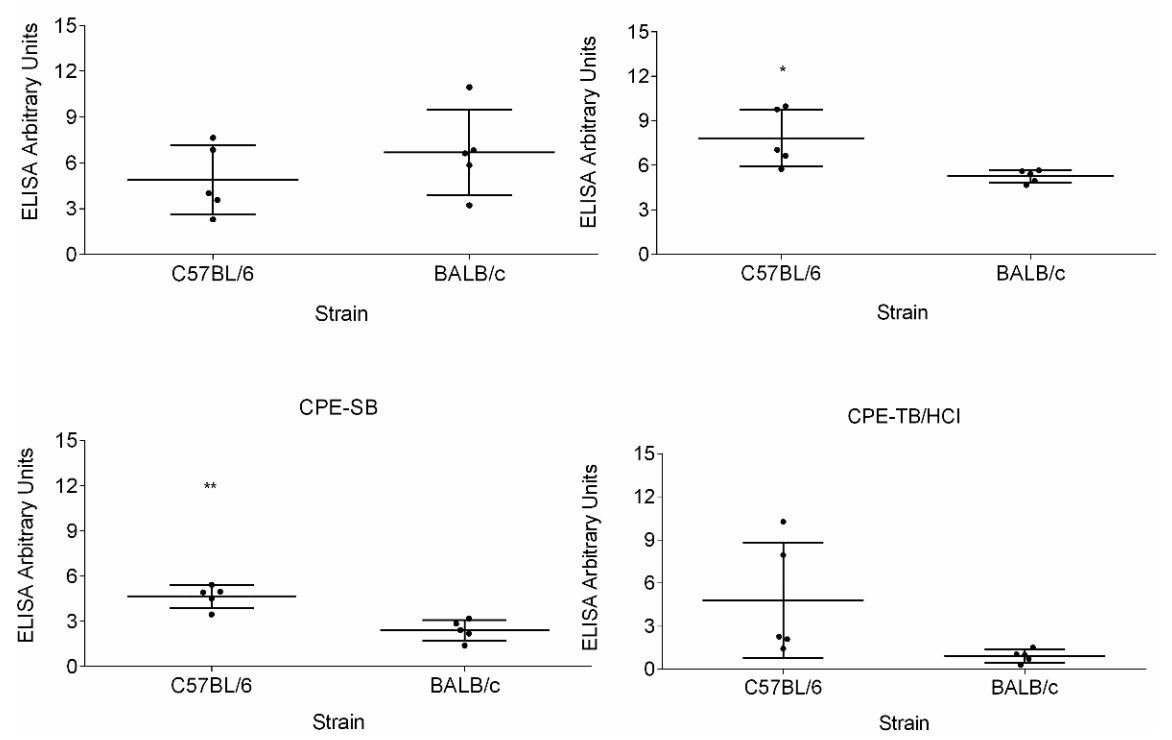

Fig 7: Titers of sera from mice tested on ELISA plates adsorbed with antigens corresponding to immunization. Comparison between C57BL / 6 and Balb/c titers sensitized with CPE. $\mathrm{N}=5 . \mathrm{p}<0.05$ ${ }^{*} ; \mathrm{p}<0.01={ }^{* *} ; \mathrm{p}<0.001={ }^{* * *} ; \mathrm{p}<0.0001=* * * *$

Simulating a situation where individuals are sensitized with antigens processed in different ways, and that Elisa Kits preparation are not homogeneous we set up a heat map matrix to observe the reactivity pattern (Fig 8). As described in the previous results and sinthesisted here both sensitization protocols and coating of the ELISA plate influence reactivity.

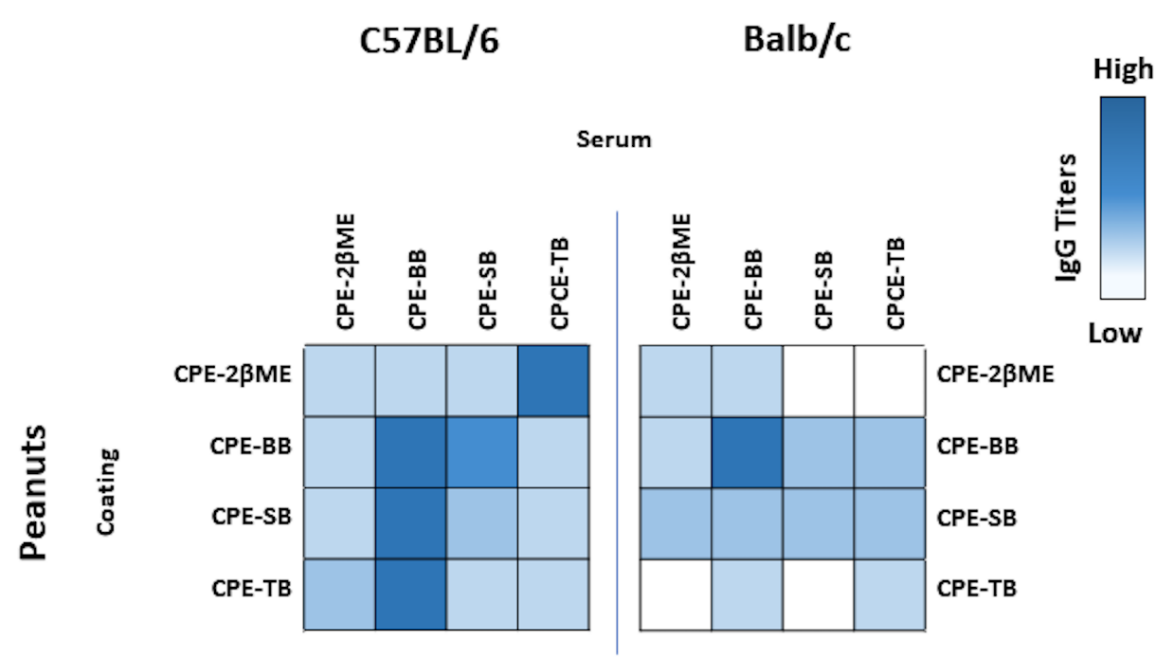

Fig 8. Clustering of anti seed IgG titers. Matrix established crossing administered protein, protein used to coat ELISA plates and mouse strain.

\section{DISCUSSION}


A diet containing immunogenic proteins is extremely important for the maintenance of the immune system homeostasis [19]. But what makes a dietary protein a food allergen? This has not yet been fully established. The knowledge about the factors that determine the allergenicity of food proteins is still incomplete. In theory any protein contained in foods could induce allergy, however, as stated before 14 are responsible for over $90 \%$ of all allergies.

From the immunogenicity point of view peanut is one of the best studied seed. The World Health Organization/International Union of Immunological Societies (WHO/IUIS) Allergen Nomenclature Subcommittee recognizes 17 distinct peanut allergens.

In order to perform in vivo or in vitro diagnostic tests, standardized antigens are fundamental. Early characterization of peanut allergen utilized serum from allergic patients to prepare affinity columns. The study of the eluted proteins permitted the molecular characterization of the major allergens [20]. Since the 1980's several molecular biology strategies were developed and are currently being used to produce purified proteins both from food in naturaas well as recombinant proteins. Purified antigens in diagnostic allergy tests are not necessarily more effective than complex protein solutions [21]. Albeit all efforts there are still inconsistencies between manufacturers of food allergens which may turn the tests unreliable in the clinical setting [22].

We prepared peanut extracts using four different buffers ranging in $\mathrm{pH}$ from 6.8 to 10.0. Quantitively, the highest yield was obtained with the alkaline borate buffer with the addition of $\beta$-mercaptoethanol, a disulfide bond reducing agent. Regarding the other three buffers we observed that neutral SB extracted more peanut protein than both alkaline BB and acid TB. We did not find in the literature explanation for this fact.

The Brazilian Table of Food Composition (TACO) research group obtained each food from the five Brazilian macro regions, then analyzed its micro and macro elements [23]. The food table refers to the average value of each component contained in the respective foods. It is important to note that the analytical method used to quantify may overestimate or underestimate the protein content of the foodstuff. Protein quantification in the TACO study was performed by the Kjeldahl method that determines the total nitrogen contents which was then converted to protein concentration [24-26]. Our results using the Lowry [11] protein quantification method agree with the TACO results [23]. We can argue that the use of $\beta$-mercaptoethanol may have better exposed reactive sites of the protein content than the other three buffers.

Having obtained the protein extracts we determined the immunogenicity of each extract by performing a routine sensitization protocol with alum, an adjuvant typically used to induce TH2 responses [27] in contrast to Freud adjuvant that is typically used to stimulate TH1 responses [21]. The two mouse strains used C57BL/6 and Balb/c - were chosen due to their Th1 and Th2 profiles, respectively[28]. To study the intrinsic immunogenicity of allergens and the influence of the food matrix, van Wijk, Nierkens (29) compared the in vivo(subcutaneous) response to purified peanut allergens and to CPE similar to the extracts used in this work. These authors inform that none of the purified allergens induced significant immune activation while, $\mathrm{CPE}$ induced an increased immune response to the individual allergens. In accordance with the authors, one must argue that purified proteins injected in the subcutaneous tissue without an inducer of inflammation may be immunogenic in the long run but, most probably, not after a single inoculation. For example, as seem in the clinical scenario, with the use of bovine or porcine insulin by diabetic patients that frequently develop resistance to the daily injected insulin [30].

Although defatting the milled seeds is a common procedure in protein purification, we did not include this step prior to the extraction procedures, taking in account that the ingested food is, in general, not in a defatted condition. However, during the extraction process (incubation and centrifugation) most of the fat was removed as it comes out of phase. The amount of reminiscent fat may have influenced the immunogenicity of each extract. A frequently used immunopotentiator is incomplete Freund's adjuvant, a mineral oil, in which antigen solutions are emulsified [31]. The possible influence of the different buffers on the separation of the fat contained in the seeds was not calculated.

Both cooked and raw food undergo harsh physical and chemical reactions before it can be absorbed by 
the gut. The majority must be broken down to the elemental components for absorption, however, to continue immunogenic and induce allergy some of the molecules must resist processing. Only to site a few, potential influencers of allergenicity are: food matrix [29], protein stability during processing [32], and the immunological status of the entry port as has been previously demonstrated by our group [33].

In general, our data agree with those of the literature [34,35] regarding the ionic strength of the buffer used in the extraction of peanut proteins. However, different from these authors the use of the reducing agent increased the extraction efficiency in our model. The difference between the two protocols consists in the buffer and the reducing agents used. We used an acid while they used an alkaline tris buffer and we used $\beta \mathrm{ME}$ and they used SDS and other reducing agents. As proposed by these authors the CPE is immunogenic as it is a complex mixture of proteins, carbohydrates, and fatty acids. The latter be responsible for the adjuvant effect due to their inflammatory potential. [29].

As can be seen in the gel electrophoresis the profile of protein bands is influenced by the extraction buffer used. Although similar molecular weight proteins are extracted by each of the extraction buffers, none of them successfully extracted all proteins from peanuts. In our experiment, all protein extracts are immunogenic. All animals produced significantly more antibodies to the Ag-alum solution than their sham counterparts. Irrespective of which protein extract was inoculated or adsorbed to the Elisa plate positive reactivity was observed. However, the intensity of serum reactivity varied. C57BL/6 mice sensitized with one of the four peanut extracts did not show significant differences when the plates were adsorbed with CPE- BB2ßME or $\mathrm{CPE}-\mathrm{TB} / \mathrm{HCl}$. These results suggest a dominance in the immunogenicity of the protein profile that was obtained by these two buffers. On the other hand, the same sera show distinct reactivity profiles when the plates are coated with CPE-BB or CPE-SB. Our hypothesis is that the immunogenicity of each CPE differs and induces distinct antibody profiles. This hypothesis has not yet been tested. We are currently performing further experiments to elucidate this fact.

Each CPE induced different intragroup variability. C57BL/6 mice sensitized with CPE-SB presented more homogeneous reactivities when compared to those sensitized with $\mathrm{CPE}-\mathrm{TB} / \mathrm{HCl}$ which presented quite heterogeneous reactivities. Some individuals with high levels and others with low levels of anti-peanut antibodies. This pattern of response was less prevalent in Balb/c mice, being visualized only in animals inoculated with CPE-2 $\beta \mathrm{ME}$ and tested with plates adsorbed with the homologous extract. In populations with a heterogeneous genetic profile, one would expect a pattern of intragroup discrepancies however the experiments were undertaken with inbred mouse strains. We found no similar findings in the literature and our working hypothesis is that the animals' microbiota may be influencing their responses, since the animals used were neither SPF nor germ-free.

The mean reactivity of sera from the $\mathrm{C} 57 \mathrm{BL} / 6$ and $\mathrm{Balb} / \mathrm{c}$ mice sensitized with one of the four peanut extracts varied according to the extract used for adsorption on the plates. The mean reactivity titers of sera plated on CPE-2ßME were lower than the remaining plates suggesting that either its adhesion is less effective or that 2ßME decreases the immunogenic capacity of this extract as it dissociates disulfide bonds. The latter is supported by the fact that immunizations with this extract also yields lower antibody titers on plates covered with the extracts obtained with other buffers (CPE-BB, CPE-SB and CPE-TB / HCl).

The immunoblotting revealed that the pattern of sera reactivity to the corresponding extract used to sensitize also varies according to the CPE used. Astuti et al found that peanut allergen induced individual specificity patterns, suggesting that it is better to use CPE rather than purified proteins as a tool for diagnosing allergies, since immunodominance may vary due to food processing, absorption and physiology therefore, each individual may be allergic to different allergens of any food [36].

We did not observe differences in the comparison of the mean reactivities of sera from $\mathrm{C} 57 \mathrm{BL} / 6$ mice sensitized with one of the four peanut extracts and tested on an ELISA plate adsorbed with the homologous extract. In this lineage although the average reactivity for the peanut was not significantly affected it is possible to observe the great intragroup dispersion with some animals responding more than others. This observation is not the result of possible inter-plate variations because all the sera from a same group were 
evaluated on the same plate suggesting the interference of biological factors in the response to the peanut by C57BL/6 mice.

This scenario is different for the Balb/c mice sensitized with the peanut extracts. The form of extraction clearly alters the reactivity. $\mathrm{CPE}-\mathrm{TB} / \mathrm{HCl}$ showed the lowest titers. In this lineage only those inoculated with CPE-BB2 $\beta M E$ showed a large dispersion in anti-peanut polyisotypic $\mathrm{IgG}$ titers. Although CPE-TB/HCl yielded the lowest protein concentration, this fact does not justify the low antibody titers since all the animals were inoculated with $100 \mu \mathrm{g}$ of antigen independent of the extract, suggesting that genetic factors of the lineage associated with the differentiated immunogenicity of the extracts influenced the observed immune response.

\section{Conclusion}

Buffers with different characteristics, (salts, ionic strength and use of reducing agents) influence the profile of protein solutions during the extraction process which in turn may influence the comparability of distinct Allergy tests. All four buffers used in this work were suitable for the extraction of immunogenic proteins from peanuts. Our results demonstrate the need to use more than one protein profile to prevent possible false negatives in in vitro and in vivo allergy tests.

\section{Acknowledgments}

The authors would like to thank the Coordenação de Aperfeiçoamento de Pessoal de Nível Superior (CAPES) - Coordination for the Improvement of Higher Education Personnel (CAPES) and the Conselho Nacional de Desenvolvimento Científico e Tecnológico (CNPq) - National Council for Scientific and Technological Development $(\mathrm{CNPq})$ for their financial support.

\section{References}

1. Ilinskaya AN, Dobrovolskaia MA. Understanding the immunogenicity and antigenicity of nanomaterials: Past, present and future. Toxicol Appl Pharmacol. 2016;299:70-7. Epub 2016/01/17. doi: 10.1016/j.taap.2016.01.005. PubMed PMID: 26773813; PubMed Central PMCID: PMCPMC4811736.

2. Gupta R, Holdford D, Bilaver L, Dyer A, Holl JL, Meltzer D. The economic impact of childhood food allergy in the United States. JAMA pediatrics. 2013;167(11):1026-31. doi: 10.1001/jamapediatrics.2013.2376. PubMed PMID: 24042236.

3. Allergen Bureau. Allergen Bureau Home Page 2019 [updated Access on: 12/12/2019.]. Available from: http://allergenbureau.net/food-allergens/.

4. Hagenmeyer M. Food information regulation: Commentary on regulation (EU) No. 1169/2011 on the provision of food information to consumers: Lexxion Verlagsgesellschaft; 2012.

5. Bollinger ME, Dahlquist LM, Mudd K, Sonntag C, Dillinger L, McKenna K. The impact of food allergy on the daily activities of children and their families. Annals of Allergy, Asthma \& Immunology. 2006;96(3):41521. doi: 10.1016/S1081-1206(10)60908-8.

6. FDA. Food and Drug Administration Home Page 2019 [updated Access on: 12/12/2019.]. Available from: https://www.fda.gov/food/food-ingredients-packaging/food-allergens.

7. Morais Cea. Métodos experimentais no estudo de proteínas.: Instituto Oswaldo Cruz; 2013. 84 p.

8. Landry J, Moureaux T. [Heterogeneity of corn seed glutelin: selective extraction and amino acid composition of the 3 isolated fractions]. Bulletin de la Societe de chimie biologique. 1970;52(10):1021-37. Epub 1970/01/01. PubMed PMID: 5511741.

9. Maehre HK, Dalheim L, Edvinsen GK, Elvevoll EO, Jensen IJ. Protein Determination-Method Matters. Foods. 2018;7(1). doi: 10.3390/foods7010005. PubMed PMID: 29301260; PubMed Central PMCID: PMC5789268. 
10. Nwachukwu ID, Aluko RE. A systematic evaluation of various methods for quantifying food protein hydrolysate peptides. Food Chemistry. 2019;270:25-31. doi: https://doi.org/10.1016/j.foodchem.2018.07.054.

11. Lowry OH, Rosebrough NJ, Farr AL, Randall RJ. Protein measurement with the Folin phenol reagent. The Journal of biological chemistry. 1951;193(1):265-75. Epub 1951/11/01. PubMed PMID: 14907713.

12. Teixeira GAPB. Seleção de dietas por camundongos normais imunes e tolerantes a amendoim e castanha de caju [Masters]: Universidade Federal de Minas Gerais; 1995.

13. Laemmli UK. Cleavage of structural proteins during the assembly of the head of bacteriophage T4. nature. 1970;227(5259):680-5.

14. Wilson K, Walker J. Principles and techniques of biochemistry and molecular biology. 7 ed. United Kingdom: Cambridge University Press; 2010. 744 p.

15. Towbin H, Staehelin T, Gordon J. Electrophoretic transfer of proteins from polyacrylamide gels to nitrocellulose sheets: procedure and some applications. Proc Natl Acad Sci U S A. 1979;76(9):4350-4. doi: 10.1073/pnas.76.9.4350. PubMed PMID: 388439; PubMed Central PMCID: PMCPMC411572.

16. Kilkenny C, Browne WJ, Cuthill IC, Emerson M, Altman DG. Improving bioscience research reporting: the ARRIVE guidelines for reporting animal research. Osteoarthritis Cartilage. 2012;20(4):256-60. Epub 2012/03/20. doi: 10.1016/j.joca.2012.02.010. PubMed PMID: 22424462.

17. Tanner RS, James SAJJoim, biotechnology. Rapid bactericidal effect of low pH against Pseudomonas aeruginosa. 1992;10(3-4):229-32.

18. Whipple B, Agar J, Zhao J, Pearce DA, Kovács ADJSr. The acidified drinking water-induced changes in the behavior and gut microbiota of wild-type mice depend on the acidification mode. 2021;11(1):1-15.

19. Menezes JS, Mucida DS, Cara DC, Alvarez-Leite JI, Russo M, Vaz NM, et al. Stimulation by food proteins plays a critical role in the maturation of the immune system. Int Immunol. 2003;15(3):447-55. Epub 2003/03/06. PubMed PMID: 12618489.

20. Kemp AS, Mellis CM, Barnett D, Sharota E, Simpson J. Skin test, RAST and clinical reactions to peanut allergens in children. Clinical allergy. 1985;15(1):73-8. PubMed PMID: 3978778.

21. Stanisavljevic S, Dedovic N, Vujicic M, Saksida T, Jevtic B, Milovanovic B, et al. Strain-specific helper T cell profile in the gut-associated lymphoid tissue. Immunology letters. 2017;190:282-8. doi: 10.1016/j.imlet.2017.08.017. PubMed PMID: 28851631.

22. David NA, Penumarti A, Burks AW, Slater JE. Food allergen extracts to diagnose food-induced allergic diseases: How they are made. Annals of allergy, asthma \& immunology : official publication of the American College of Allergy, Asthma, \& Immunology. 2017;119(2):101-7. doi: 10.1016/j.anai.2016.11.008. PubMed PMID: 28801015.

23. TACO. Tabela brasileira de composição de alimentos. NEPA-Unicamp, Campinas (SP), 105p. 2011.

24. Jones DB. Factors for converting percentages of nitrogen in foods and feeds into percentages of proteins: US Department of Agriculture Washington, DC; 1941.

25. AACC. American Association of Cereal Chemists. Approved methods of the American association of cereal chemists. Vol 1 e 2. 9 ed. Saint Paul : AACC; 1995.

26. AOAC. Official methods of analysis of AOAC international. 17a ed. 2000.

27. Fierens K, Kool M. The mechanism of adjuvanticity of aluminium-containing formulas. Current pharmaceutical design. 2012;18(16):2305-13. PubMed PMID: 22390693.

28. JAX. The Jackson Laboratory 2020 [updated access on: 12/12/2020]. Available from: https://www.jax.org/. 
29. van Wijk F, Nierkens S, Hassing I, Feijen M, Koppelman SJ, de Jong GA, et al. The effect of the food matrix on in vivo immune responses to purified peanut allergens. Toxicol Sci. 2005;86(2):333-41. doi: 10.1093/toxsci/kfi187. PubMed PMID: 15858220.

30. Landgraf W, Sandow J. Recombinant Human Insulins - Clinical Efficacy and Safety in Diabetes Therapy. Eur Endocrinol. 2016;12(1):12-7. Epub 2016/03/01. doi: 10.17925/EE.2016.12.01.12. PubMed PMID: 29632581; PubMed Central PMCID: PMCPMC5813452.

31. Herbert WJ. The mode of action of mineral-oil emulsion adjuvants on antibody production in mice. Immunology. 1968;14(3):301-18. PubMed PMID: 4170508; PubMed Central PMCID: PMCPMC1409334.

32. Pekar J, Ret D, Untersmayr E. Stability of allergens. Mol Immunol. 2018;100:14-20. doi: 10.1016/j.molimm.2018.03.017. PubMed PMID: 29606336; PubMed Central PMCID: PMCPMC6020993.

33. Paschoal PO, Campos SM, Pedruzzi MM, Garrido V, Bisso M, Antunes DM, et al. Food allergy/hypersensitivity: antigenicity or timing? Immunobiology. 2009;214(4):269-78. doi: 10.1016/j.imbio.2008.09.007. PubMed PMID: 19327544.

34. Sathe SK, Venkatachalam M, Sharma GM, Kshirsagar HH, Teuber SS, Roux KH. Solubilization and electrophoretic characterization of select edible nut seed proteins. Journal of agricultural and food chemistry. 2009;57(17):7846-56. doi: 10.1021/jf9016338. PubMed PMID: 19655801.

35. Walczyk NE, Smith PMC, Tovey ER, Roberts TH. Peanut protein extraction conditions strongly influence yield of allergens Ara h 1 and 2 and sensitivity of immunoassays. Food Chem. 2017;221:335-44. doi: 10.1016/j.foodchem.2016.10.063. PubMed PMID: 27979211.

36. Astuti R, Palupi N, Zakaria F. Quality performance of protein allergen isolates for allergy diagnostic test (Case: Indonesian soybeans (Glycine max) and peanuts (Arachis hypogaea)). International Food Research Journal. 2018;25(1).

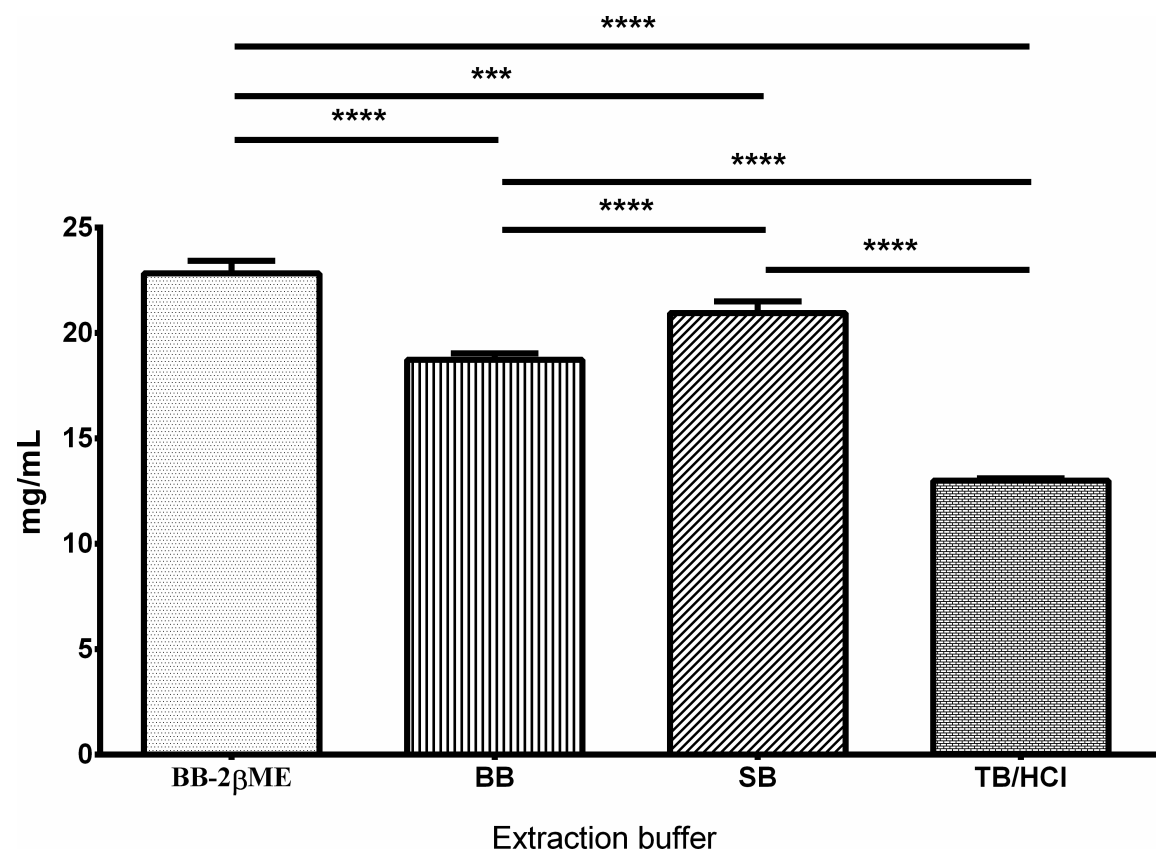




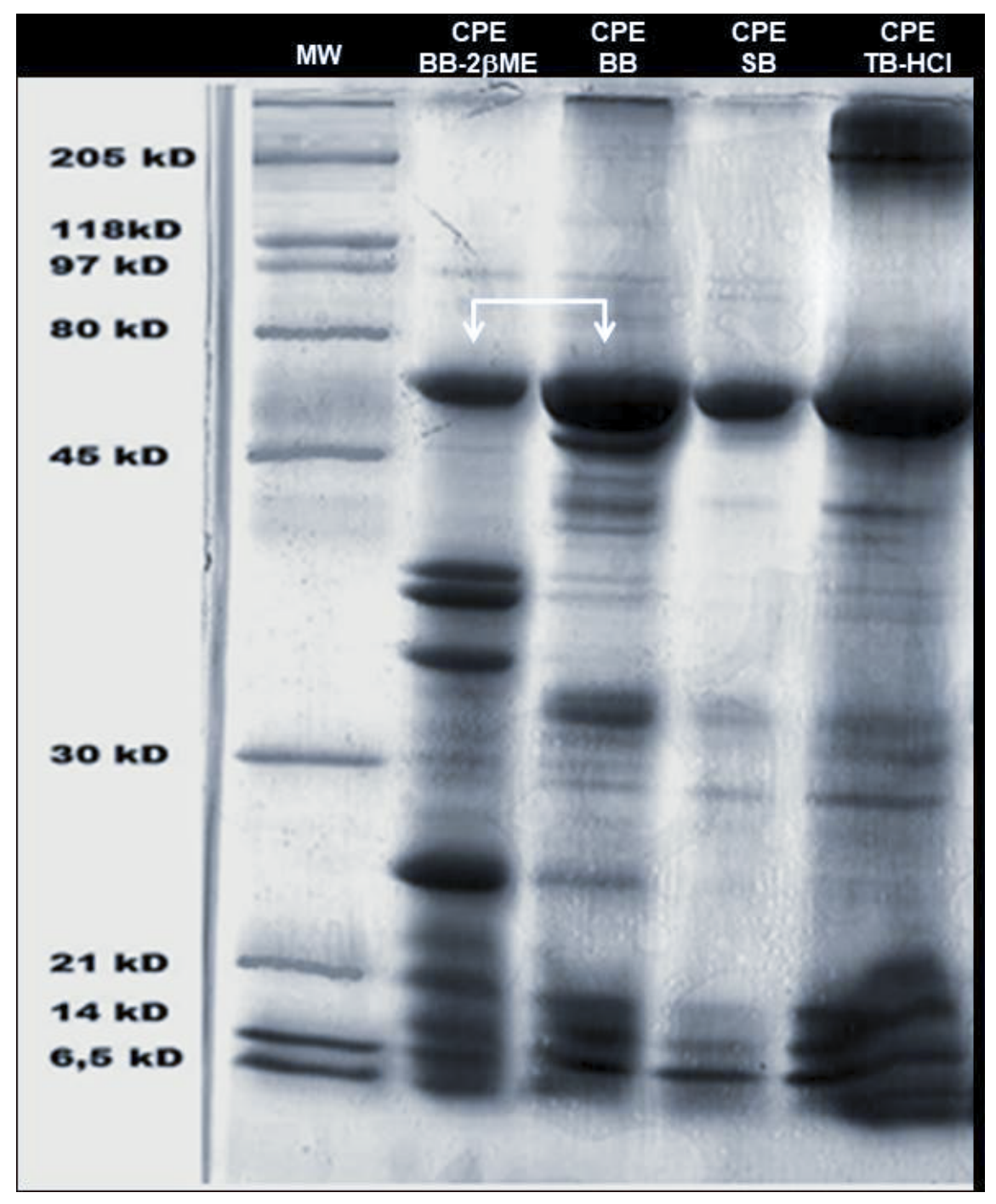




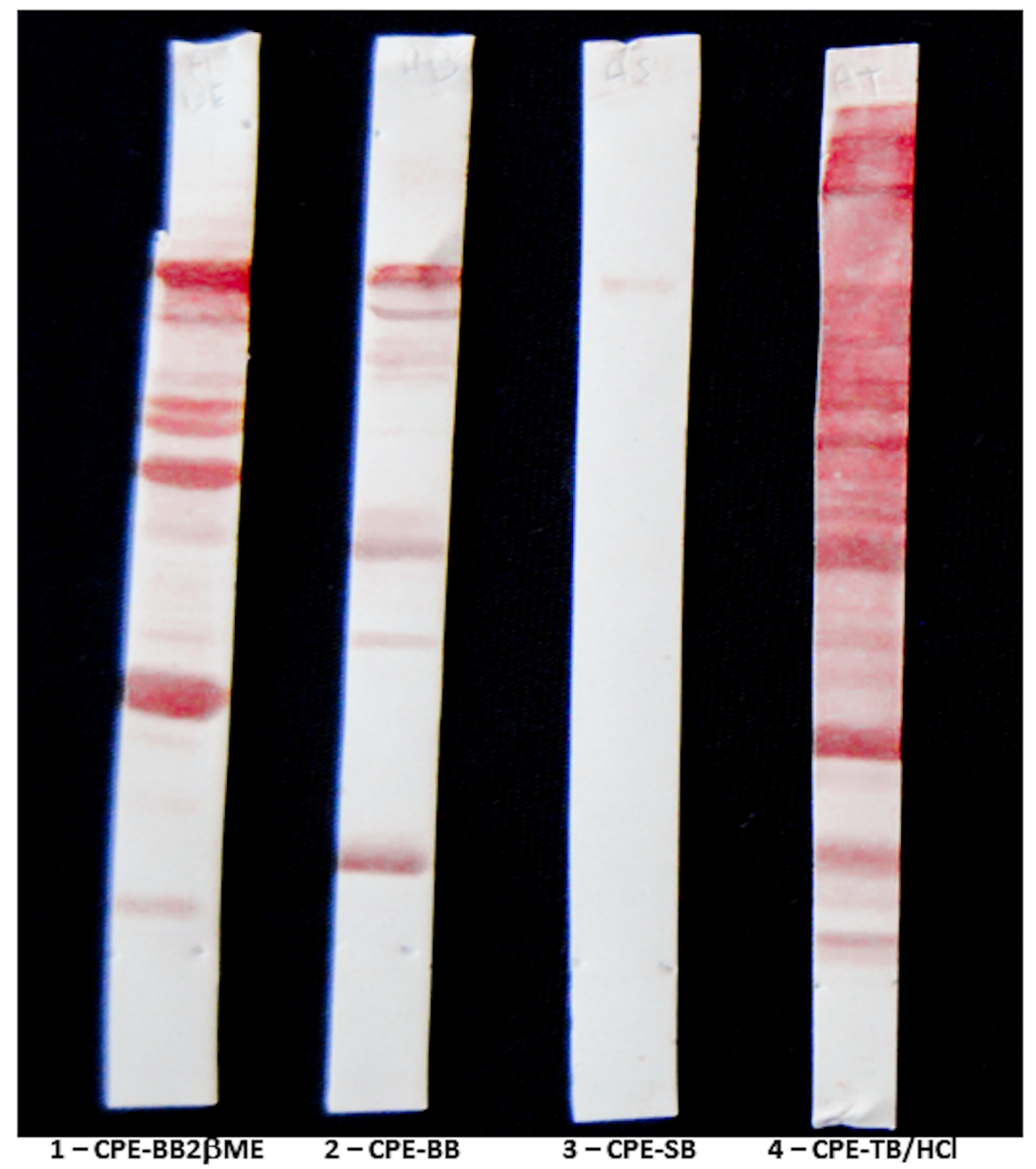

C57BL/6

A

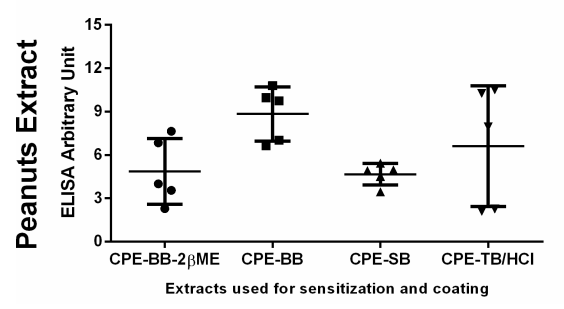

BALB/c

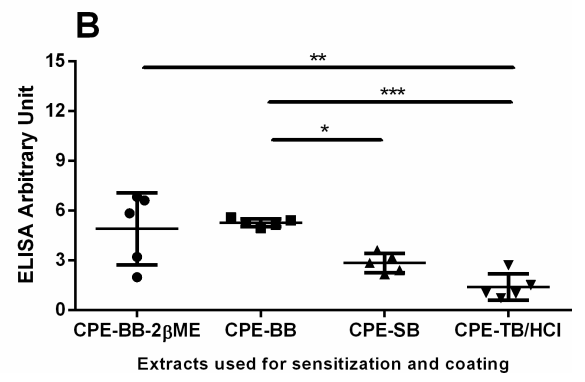


C57BL/6

A Plates coated with CPE-BB-2 $\beta M E$

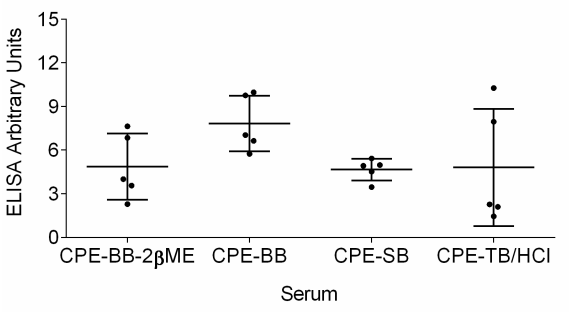

C

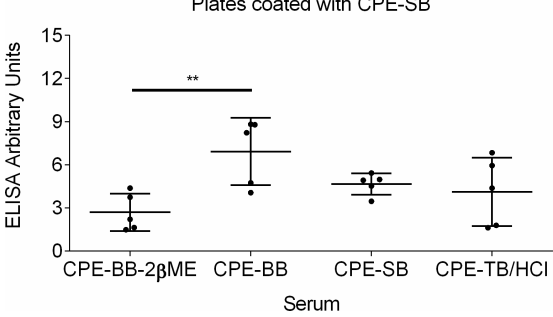

B

Plates coated with CPE-BB

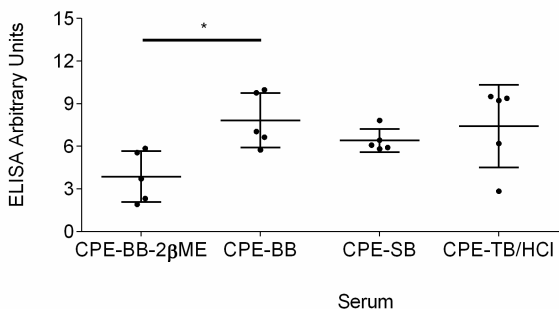

D

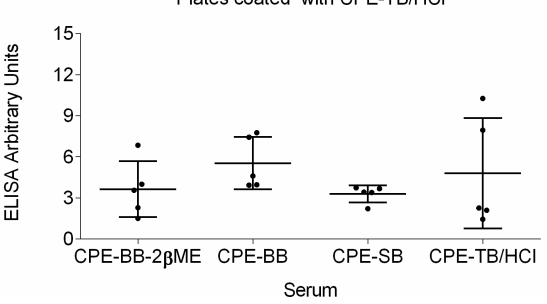

\section{BALB/c}

A Plates coated with CPE-BB-2 $\beta M E$

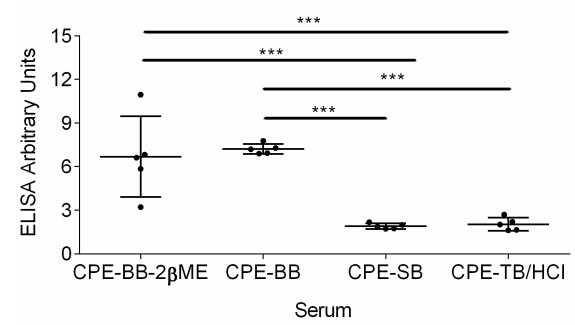

C

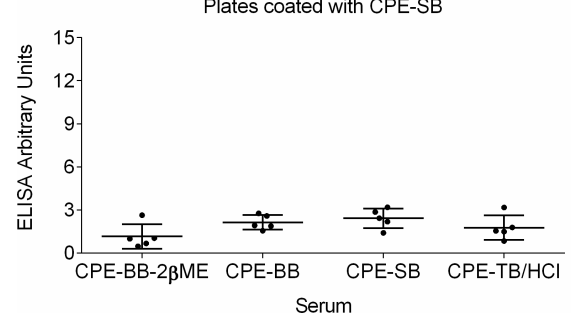

B

Plates coated with CPE-BB

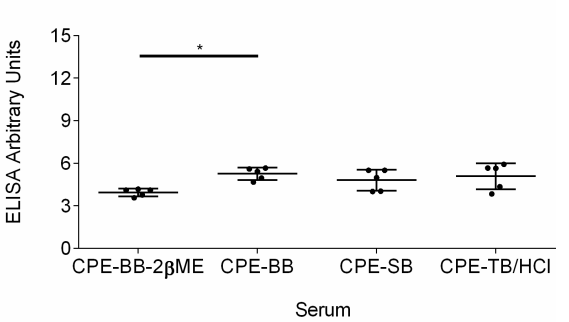

D

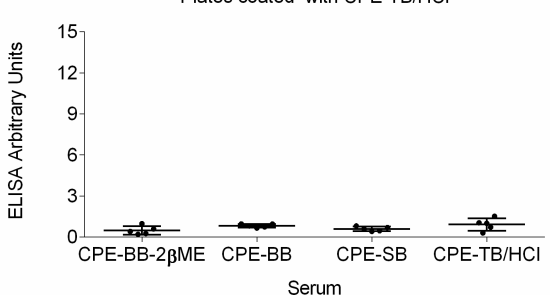


CPE-BB-2 $\beta M E$

CPE-BB
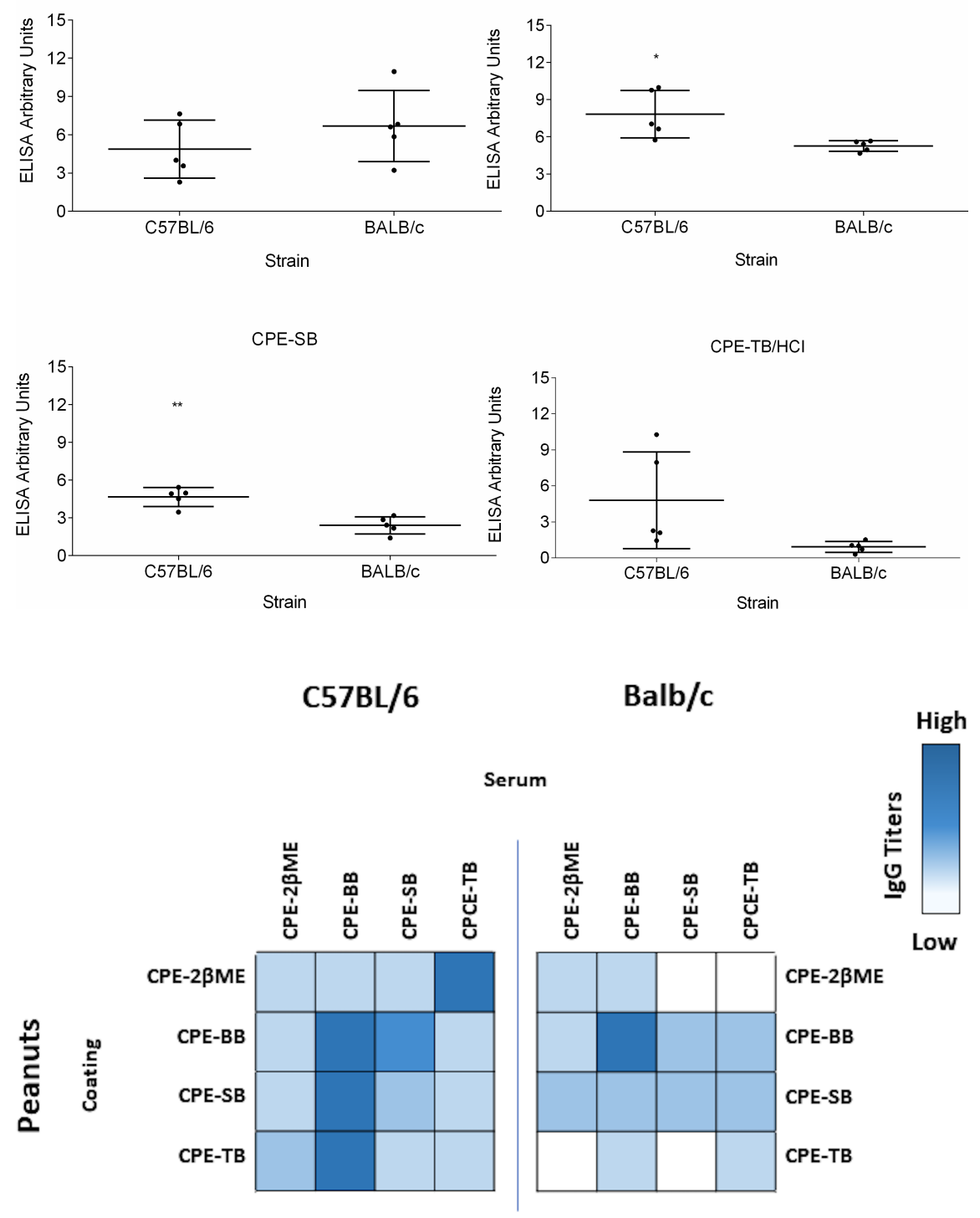